\title{
Analyses of burn-out among medical professionals and suggested solutions - a narrative review
}

\author{
Maged Tanios $^{1,2}$, David Haberman ${ }^{3}$, John Bouchard ${ }^{4}$, Michael Motherwell ${ }^{5}$, Jay Patel ${ }^{2,6}$ \\ ${ }^{1}$ Sound Critical Care, Tacoma, WA, USA; ${ }^{2}$ Department of Medicine, MemorialCare, Long Beach Medical Center, Long Beach, CA, USA; \\ ${ }^{3}$ Haberman Pharmaceuticals LLC, Washington, DC, USA; ${ }^{4}$ Cumberland Consulting Group, A Tegria Company, Franklin, TN, USA; ${ }^{5}$ Orthopedic \\ Administration, Henry Ford Health System, Detroit, MI, USA; ${ }^{6}$ University of California, Irvine, CA, USA \\ Contributions: (I) Conception and design: M Tanios, D Haberman, J Bouchard, M Motherwell; (II) Administrative support: None; (III) Provision of \\ study materials or patients: None; (IV) Collection and assembly of data: M Tanios, D Haberman, J Bouchard, M Motherwell; (V) Data analysis and \\ interpretation: None; (VI) Manuscript writing: All authors; (VII) Final approval of manuscript: All authors. \\ Correspondence to: Maged Tanios, MD, MPH. 3605 Long Beach Blvd, \#405. Long Beach, CA 90807, USA. Email: mtanios@memorialcare.org.
}

\begin{abstract}
The increasing complexity of healthcare delivery in the United States and the financial challenges of meeting the escalating costs pose significant pressures on physicians, healthcare providers, and their teams. These various demands put physicians at high-risk for extreme mental fatigue, which affects their occupational performance and their patient's well-being, and the healthcare delivery systems in general. Moreover, burned-out doctors are at risk exiting healthcare altogether leading to reduction patients' access and continuity of care. In this paper, we performed a selective review of the literature related to health care associated burnout and utilize double-loop learning to offer opinions and selected solutions for physicians and healthcare organizations for interventions to minimize burnout and reverse its occurrence in the workplace and at home. Moreover, this paper will analyze the significant contributors to burnout, such as a lack of proper understanding, diversity and workplace factors, absence of organizational support systems, and health record-related burdens associated with 21 st century medicine. For these reasons, the authors recommend a multifaceted approach that includes flexible scheduling, mental health education, and support systems. Other intervention areas include home-work balance, organizational interventions, and financial remedies for rewarding performance - by altering incentivization schedules. The approach considers a single and double-loop approach for medical establishments and their respective infrastructures
\end{abstract}

Keywords: Healthcare providers; burnout; burnout syndrome; work-life balance; autonomy; clinically integrated network (CIN)

Received: 08 December 2020; Accepted: 10 May 2021; Published: 25 March 2022.

doi: $10.21037 /$ jhmhp-20-153

View this article at: http://dx.doi.org/10.21037/jhmhp-20-153

\section{Introduction}

Healthcare in the United States is a $\$ 3.5$ trillion industry and has experienced tremendous growth per year (1). By 2024, it is expected that this sector will be the largest employer type in the country. However, such data suggest a growing gap between available jobs and actual hires in the healthcare sector (2). As the population continues to grow and individuals gain greater longevity, it is projected that the increasing service demand will require upwards of 2.3 million healthcare workers. This may result in a shortage within the entire spectrum of skilled health workforces, such as physicians, nurses, and technologists (3).

Importantly, this deficit's primary contributing element is the occupational hazard known colloquially as "burnout."

^ ORCID: 0000-0002-4103-6099. 
Maslach identifies a three-dimensional definition of burnout as, "overwhelming exhaustion, feelings of cynicism and detachment from the job, and a sense of ineffectiveness and lack of accomplishment." Exhaustion refers to physiological manifestations such as energy loss, depletion, and fatigue. Whereas cynicism, also known as depersonalization and inefficacy, are largely somatic responses to long-term job stress (4). Interestingly, burnout is not a new phenomenon: the first article featuring the topic was published in 1974. Soon thereafter, Maslach created the Maslach Burnout Inventory to empirically measure each term's dimension (5). Nurses and Physician Assistants (43\%), residents (69\%), and medical students (44\%) all experience some level of burnout (6). However, physicians experience burnout at a higher rate of $54 \%$, significantly surpassing other clinical positions (7). The cost to healthcare attributable to physician burnout is estimated at between $\$ 2.6$ to 6.3 billion USD per annum. The annual cost to an organization from physician's turnover and reduced hours is estimated at $\$ 7,600$ per employed physician (via the fiscal deficit from lost workforce hours and low patient maintenance) (8). Powell points to increased hours, high turnover rates, and job replacements as leading cost drivers associated with physical exhaustion in doctors (9).

Furthermore, medical specialty and job title show variability in burnout rates. For example, specialty medicine such as urology, neurology, physical medicine, and internal medicine experience burnout at a disproportionately greater prevalence. Urology has a burnout rate of $54 \%$ among physicians, which is the highest of all specialties (10).

It is vital to consider the validity of burnout and if the socalled syndrome can negatively impact patient care. Several studies have concluded that providers experiencing burnout are twice as likely to receive poor patient satisfaction or low professionalism scores. Until recently, a direct correlation between clinical outcomes and burnout had not been identified. Thus, providers suffering from the syndrome double the risk of an adverse patient safety event due to inattention to detail, diminished cognitive function and increased safety lapses. An article published in the British Medical fournal exemplified such evidence by concluding that there is moderate evidence to suggest an association between burnout and suboptimal care resulting in medical errors (11).

Moreover, the impact of physician burnout is felt far beyond the walls of the hospital. A General Surgeon writes, "my relationships have withered...my family is frustrated. We rarely make plans to do anything socially as they are likely to be canceled". Based on a recent review of nearly 80,000 health care workers anxiety, depression, stress, posttraumatic stress disorder and insomnia are increasingly being reported as cofactors of burnout (12). Practitioners experiencing burnout are more likely to get divorced, suffer from addiction, and commit suicide. About one physician per day commits suicide, which is the highest rate among all professions. Physicians are more than twice as likely to commit suicide than the general population (10).

Furthermore, research suggests that the far majority, $64 \%$, of practitioners do not seek help for burnout or depression because they do not believe the symptoms are severe enough to warrant medical intervention (10). Health professionals experiencing burnout do not have adequate awareness of their syndrome nor the appropriate resources to cope with it. Only $45 \%$ of healthcare organizations offer a workplace program to reduce stress or burnout. This shows that inadequate resources and education are available to medical professionals regarding burnout syndrome, and such deficiency in care results in instability in both the personal and professional spheres (10). We present the following article in accordance with the Narrative Review reporting checklist (available at https://jhmhp.amegroups. com/article/view/10.21037/jhmhp-20-153/rc).

\section{Scope and background of the problem}

Health organizations are partly responsible for the workrelated factors that contribute to workforce burnout. Providers are expected to ensure high quality, patientcentered care without adequate resources. Yet, productivity and throughput expectations are unreasonably high for clinical staff. The amount of time spent with each patient continues to decrease as health systems push providers to meet quotas for reimbursement (13). This shows that the increased demands on physicians and medical personnel (to meet patient quotas and provide exemplary levels of care) can possess negative consequences in the output of patient care.

Furthermore, there is a direct correlation between the number of hours worked and lower job satisfaction, which contributes to burnout. The average U.S. physician works 51 hours per week, and $25 \%$ work greater than 60 hours. Residents are constantly on-call, may work up to 80 hours per week, and have single 24-hour shifts with inadequate breaks in-between. Annually, no other whitecollar profession falls within $50 \%$ of the number of hours worked by residents. Professional organizations, such as the Accreditation Council for Graduate Medical Education 
(ACGME), have implemented hours worked restrictions to help young physicians avoid burnout. However, there is little evidence to support that this alone has yielded positive outcomes (14).

The American Recovery and Reinvestment Act (ARRA Pub.L. 111-5 of 2009) requires healthcare providers to adopt and implement meaningful use of electronic medical records. Meaningful use refers to the utilization of secure electronic documentation to improve care coordination, quality, and engagement with patients. Those who do not comply with such regulations are subject to a $1 \%$ reduction of Medicare reimbursements (15). Electronic medical record (EMR) infrastructures eliminated simple paper notes and were supposed to be more cost-effective; however, it created a new, overwhelming, and time-consuming process for providers. Research shows that emergency medicine physicians could go through 4,000 mouse clicks during a 10-hour shift. The amount of time electronic documentation outweighs the time spent with the patient (16). A study from the University of New Mexico suggests that physicians spend double the amount of time on the computer than with a patient, which results in completing documentation during off-hours. It is reported that $40 \%$ of physicians have stress directly associated with the EMR (17). This demonstrates that the excessive amount of time doctors and medical workers spend on documentation diminishes their interaction with patients and may decrease the quality of care received.

Also, bureaucratic tasks place an additional burden on healthcare practitioners and contribute to workforce burnout. It is estimated that physicians spend double the amount of time with administrative forms compared to providing direct patient care. Hence, correspondence with insurance companies, Medicare, and Medicaid all represent additional stressors to medical employees. Furthermore, the intensely scrutinized documentation and clinical practice by regulatory bodies compound the already high professional expectations (18).

Fortunately, many professionals never have to partake in life-or-death situations, but it is a common occurrence for healthcare professionals. Clinicians pursue medicine to help people, yet the system places an insurmountable number of barriers to delivering quality patient care. The amount of stress the provider experience is unparalleled. Most physicians, approximately $60 \%$, would not recommend medicine as a career (18). The U.S. continues to lose outstanding individuals, and burnout is undoubtedly a primary contributing factor in this unfortunate statistic.

\section{Analysis}

Undoubtedly, advances in medicine improved outcomes and longevity; however, the emergence of additional duties increased workload volume relative to capacity (19). Over time, this imbalance resulted in widespread burnout among medical professionals. The burnout is not limited to physicians: it is well documented that other disciplines also suffer from burnout related to an increased workload. Failure to implement countermeasures to avoid work volume imbalance and foster resilience will result in physical and emotional exhaustion or burnout. Moreover, physicians are accustomed to grueling schedules and hard work; many thrive on healthcare's chaotic environment. However, doctors often become blinded to the consequences and suffer from the burnout syndrome described above. Healthcare companies must understand the drivers of burnout to be able to develop solutions. Consequently, many factors contribute to burnout:

\section{Lack of understanding of burnout syndrome}

All too often, physicians attribute manifestations of burnout to other causes, such as physical ailments or psychosomatic conditions (20). Individuals can experience stress from family, social, or financial issues that can temporarily affect their work. However, when physicians are unaware of the pressure from their daily workload imbalance, they overwhelm their coping capacity (21). If doctors are unaware that the root cause of their problems is related to burnout, they may fail to address or prevent the deterioration. Such obviousness to the factors that may precipitate burnout syndrome can be insidious, and the result is extreme stress and mental decline in the long-term. Interestingly, the adverse effects of burnout syndrome also extend to the patients: physicians suffering from burnout have stress-related insomnia, irritability, anxiety, or fatigue and are unlikely to muster the interpersonal skills required to provide a high level of care; resulting in a greater number of medical errors $(22,23)$. The emotional exhaustion and depersonalization (22) negatively affect the care, impairs the team dynamic, and demoralizes other providers $(24,25)$. This shows that the lack of acknowledgment of the disorder is a driving force between the burnout epidemic plaguing American hospitals \& clinics. 


\section{Diversity, personal factors, and work-life balance}

One study identified a correlation between burnout and excessive workload: with the assignment of a high number of tasks resulting in negative employee health and job performance. The study used a cross-sectional design and developed a questionnaire to survey 110 pharmacists on organizational climate, stressors, and workplace burnout (26). Aside from the added burden from EHRs, other work factors contributing to physicians' burnout are the long work hours, risk of malpractice suits, and frequent call duties (27). In addition, burnout can be related to personal attributes, including interpersonal relationship instability and familial obligations. Hence, leaders must recognize disparities and understand diversity management (28).

Burnout was previously believed to be a phenomenon reserved for late-career physicians. However, studies have shown that young physicians, such as residency and medical students, have twice the risk of burnout in early training stages compared to older colleagues (29) There is also a gender difference observed in the burnout syndrome: a Norwegian study observed higher exhaustion levels among women from work-home conflicts (30). Other researchers suggest that having a child younger than 21 years old or a non-medical professional spouse increases the risk for burnout (31).

\section{Autonomy at work}

With the advent of standardization, physicians perceive an erosion of their self-governance and independence. Physicians may interpret the standardized care model as infringing on their autonomy and decision-making skills. New York Cooperative analyzed a survey collected from 235 independent primary care practices in 174 small practices in New York City. Results showed a decreased rate of provider-reported burnout (13.5\%) for physicians who self-identified as in-control over their work environment and with more decision-making process (32). A national evaluation of 10,284 physicians and advanced practice clinicians in 1,380 smaller practices examined the relation of burnout to specific structural, organizational, and contextual characteristics of the practice environment. The study concluded that non-solo practices, practice affiliation with a healthcare system, and Federally Qualified Health Center status contributed to a higher burnout rate. In contrast, neither the practice-level patient volume nor payor mix was associated with burnout (33). Interestingly, participation in an Accountable Care Organization (ACO) was associated with burnout. Researchers concluded that members of solo practices are less likely to report burnout, suggesting that autonomy at the practice level may be an important determinant of such mental exhaustion. This finding indicates that burnout can be closely tied to the practice culture and infrastructure. It also suggests that system changes may reduce the factors leading to burnout, such as instituting greater autonomy in the workplace; erstwhile diminishing "micromanaging" of physicians in the workplace.

\section{Absence of organization support}

Administrators fail to use Kotter et al. 2016's "Leading Change: Why Transformation Efforts Fail" approach in implementing new rules or initiatives, including establishing a sense of urgency, creating a strong coalition of individuals, creating \& communicating a unifying vision and implementing changes to foster growth in the organization (34). These principles embrace the value of the healthcare professional in the success of the institution therefore increasing the importance of prevention and treatment of burnout. Furthermore, physicians may feel that administrators do not seek input or support from the professionals on the front line of healthcare (35). Organizational factors such as negative leadership behavior, insufficient reward systems, and absence of social support influence burnout rates $(31,36)$. Healthcare leaders with a good understanding of teamwork and "enabling conditions" can effectively communicate the compelling direction, implement a supportive context, and develop a shared mindset with the organization (24). This approach has been demonstrated to provide physicians with a friendly workplace resulting in a higher level of professional satisfaction and lower reported stress (37).

\section{Health record related burden}

The participation in the meaningful use program imposed significant burdens on physicians from the requirement of generating reports on quality measures (38). It is estimated that $25 \%$ of burnout is attributed (partly) to EHRs related burdens. Physicians encountered numerous challenges in producing the reports needed for participation in the Medicare Access and CHIP Reauthorization act of 2015 (MACRA), thereby increasing the stress levels and 


\begin{tabular}{|c|c|c|c|c|}
\hline \multirow[b]{2}{*}{ EHR Task Category } & \multicolumn{3}{|c|}{$\begin{array}{l}\text { Time Spent } \\
\text { per Day, min }\end{array}$} & \multirow{2}{*}{$\begin{array}{l}\text { Total Time } \\
\text { Spent per Day, } \\
\text { min (\% of } \\
\text { Daily Total) }\end{array}$} \\
\hline & $\begin{array}{l}\text { Work } \\
\text { Hours }\end{array}$ & $\begin{array}{l}\text { After } \\
\text { Hours }\end{array}$ & Ratio & \\
\hline \multicolumn{5}{|l|}{ Clerical } \\
\hline Documentation & 64 & 20 & 3.2 & $84(23.7)$ \\
\hline Order Entry & 35 & 8 & 4.4 & $43(12.1)$ \\
\hline Billing and Coding & 10 & 4 & 2.5 & $14(3.9)$ \\
\hline System Security & 8 & 2 & 4.0 & $10(2.8)$ \\
\hline Administrative & 4 & 2 & 2.0 & $6(1.7)$ \\
\hline Subtotal & 121 & 36 & 3.4 & $157(44.2)$ \\
\hline \multicolumn{5}{|l|}{ Medical care } \\
\hline Chart Review - Notes & 47 & 13 & 3.6 & $60(16.9)$ \\
\hline Chart Review - Medications & 21 & 5 & 4.2 & $26(7.3)$ \\
\hline Problem List & 8 & 4 & 2.0 & $12(3.4)$ \\
\hline $\begin{array}{c}\text { Chart Review - } \\
\text { Laboratories }\end{array}$ & 6 & 3 & 2.0 & $9(2.5)$ \\
\hline EBM, Point of Care & 2 & 2 & 10 & $4(1.1)$ \\
\hline Chart Review - Imaging & 2 & 1 & 2.0 & $3(0.8)$ \\
\hline Subtotal & 86 & 28 & 3.1 & $114(32.1)$ \\
\hline \multicolumn{5}{|l|}{ Inbox } \\
\hline $\begin{array}{l}\text { Refills and Results } \\
\text { Management }\end{array}$ & 41 & 14 & 2.9 & $55(15.5)$ \\
\hline MyChart Portal & 15 & 5 & 3.0 & $20(5.6)$ \\
\hline Telephone Call & 5 & 2 & 2.5 & $7(2.0)$ \\
\hline Letter Generation & 1 & 1 & 1.0 & $2(0.6)$ \\
\hline Subtotal & 62 & 22 & 2.8 & $84(23.7)$ \\
\hline Total & 269 & 86 & 3.1 & $355(100.0)$ \\
\hline
\end{tabular}

Figure 1 Average Time Spent Per Day by HER Task Category, Comparing Work Hours and After Hours (adapted from Arndt, 2017) (41).

minimizing the patient interaction time in the hospital setting. Consequently, the difficulty in generating the reports has risen from technical and functional limitations, disparities between clinical guidelines and EHRgenerated reports themselves, and uncertain data quality. The researchers concluded that "the current state of EHR measurement functionality may be insufficient to support federal initiatives that tie payment to clinical quality measures" (39). In another study examining 1,500 small to medium-sized practices, researchers confirmed that support is necessary to help practices obtain the data-driven Q.I. required to participate in performance-based payment programs (40). Investigators from the University of Wisconsin reported that physicians spend up to half of their workday on EHR tasks and often need additional time beyond work hours to complete their tasks (Figure 1) (41).

\section{Discussion and recommendations}

Since the problem is multifaceted, a comprehensive approach to prevention and management is of paramount importance. The approach should encompass both input and participation from healthcare societies and payors (e.g., American Medical Association, CMS), healthcare organizations, and individual physicians' efforts. The science of countermeasures does not possess data from large randomized interventional trials, thereby limiting a direct "cause and effect" causation between specific approaches and their outcomes (regarding burnout treatment). Thus, the published interventions targeted physicians with coping skills and work conditions, allowing for extrapolation for burnout syndrome potential treatments. This paper proposes the following countermeasures that may provide 
solutions to medical professional burnout's multifaceted and complex problem.

\section{Work-life balance}

Moral resilience is defined as "the capacity of an individual to sustain or restore their integrity in response to moral complexity, confusion, distress, or setbacks" (25). Building resilience through resiliency training is an integral method that may enhance "emotional tenacity" during times of stress. A study from Norway reported the risk factors for physician burnout to be related to higher exhaustion levels among women from work-home conflicts, whereas, for men, fatigue was strongly predicted by workload. With the research from diversity training as a parallel example to educate on work-life balance, one may avoid mandatory training or grievance systems (30). For these reasons, this paper recommends that organizations implement general awareness messages and emphasize the urgent need to address burnout. This is followed by providing voluntary resiliency training and support groups of burnout and moral resilience. Offering educational programs to support and cultivate moral resilience has been suggested as valuable measures to promote intra- and interdisciplinary stresses. Learnable resilience behavior enhances physicians coping skills. Resiliency fosters effective communication and encourages collaboration, which helps to manage burnout (42). Professional medical societies should also parallel the efforts by providing specialty-specific education programs.

Another known fact is that physicians often bring work "home" by long on-call hours, answering pages, and completing outstanding documentations. Dr. Drummond recommends the concept of boundary ritual to establish protected family time and achieve some work-life balance (43). Similar to Mr. Rogers' (of Mr. Roger's Neighborhood) ritual of removing his shoes, sweater and singing, "it's a Beautiful Day in the Neighborhood," We should create a ritual that signifies the transition of work life to home life.

Another recommended solution for hospitals and healthcare organizations is to adopt the Modeled on the Resilience in Stressful Events (RISE) program at Armstrong Institute for Patient Safety and Quality at Johns Hopkins University. The RISE program is designed to care for caregivers and train healthcare organizations to implement a peer-responder program that delivers "psychological first-aid" to healthcare professionals. The program "prepares employees to provide skilled, nonjudgmental and confidential support to individuals and groups" (43). Hospitals participating in the program recruit local volunteers across the various medical disciplines to educate physicians and provide support to clinicians.

\section{Workload management}

The average physician works more than $30 \%$ more per week than the general workforce (44). However, there is no established measure of workload in clinical medicine. Lilly et al. suggested establishing objective workload measures, incorporating time to complete an objective, and task frequency as important tools for burnout prevention. Further, Lilly et al. proposed a standard industrial measure termed overall equipment effectiveness (OEE) to determine the fraction of time available for Intensivists' required tasks. When the tasks are codified, physicians will be able to manage their workload and gauge the long-term sustainability of their daily efforts (45). Physicians and organizations will be able to design employee-centric jobs and implement reward systems to manage and motivate their teams using objective measures (46).

\section{Early education on burnout}

In addition, education to address burnout causes \& symptoms early in medical school (from Day 1) is invaluable in treating burnout. Hence, burnout must be addressed before residency; for example, SLU School of Medicine instituted a pass/fail system, lessened the level of detail taught in classes, and "reduce[d] student stressors [to] produce a less toxic educational environment." Also, Northwestern University's Feinberg School of Medicine instituted selfcare programs that encourage \& track personal health behaviors $(6,47)$.

Encouraging a greater peer support network is another invaluable tool in combating burnout. For instance, the Mayo Clinic demonstrated that physician solidarity with weekly meetings decreased mental exhaustion and depersonalization feelings, along with programs to increase outside-work peer interactions. Next, increasing mental-health and self-care resources for physicians (as a stigma can exist from seeking mental health by doctors-via social ostracization), by keeping after-hours, confidential treatment options, meditation, exercise, gym memberships $(6,47)$.

\section{Organizational interventions}

Finally, healthcare organizations must evaluate new models 
of implementing healthcare delivery that includes better collaboration with payors, managers, and a multidisciplinary approach to coordination of care (48). It is clear that the current models are antiquated; new models should clarify the distribution of decision-making authority at each level.

The escalating workload, paired with an unfair reward system's perception, has led physicians to grow suspicious of higher management. Thus, doctors question the motives of managers and executives and the intentions of improvement initiatives. This motive attribution asymmetry limits the trust and collaboration within an organization. The resulting "us and them" culture limits efficiency and increases physicians' stress resulting in burnout. Large healthcare organizations should encourage physicians to lead restructuring and reform within their environment. Physicians respond positively to an initiative where they feel in control and are heavily involved (49). Feedback should be devoid of stress-provoking judgment and should be useable - consistent with the data used for improvement and not judgment. Physicians are difficult to motivate; however, leaders must understand the importance of the fundamental drivers (acquire, bond, comprehend, and defend) and implement them in team motivation (46). The financial programs must be more transparent and with SMART objectives-specific, measurable, attainable, relevant, and time bound (50). The reward system is designed to be budget neutral, and the goals are nearly impossible to achieve and must be restructured. It is also important to consider the response by healthcare organizations after burnout has been established. It is clear that post-traumatic growth can be cultivated and offers an opportunity to create a more resilient healthcare worker but the appropriate mentorship and psychosocial support systems need to be in place for this to occur (51).

\section{Financial solutions for improving physician reward systems}

Preventing burnout requires multiple strategies, including goal setting and valued rewards contingent upon performance to develop a culture of performance. Organizations can improve physicians' motivation and promote empowerment by sharing information and allowing transparency in comprehending the complexity of the rewards system and productivity. Physicians usually experience a delay in earning and accumulate significant debts. For these reasons, doctors require higher salaries to realize the financial return on time invested and pay debts. A burnout prevention policy would be to implement fair productivity goals and employment packages that include debt forgiveness or assistance plan. The pay-for-performance concept rewards physicians based on performance measures that are often not aligned with outcomes and do not consider their effort or the risk for liability. Those programs are also perceived to limit physicians' autonomy, and unfairly penalize them for outcomes beyond their control. Changing the reward system to a method that aligns the physicians' effort, time, and liability will undoubtedly improve the motivation and reduce burnout. Consequently, a reward structure devised with input from physicians that incorporates a relative value unit and recognizes, and awards efforts and efficiency is advisable. Financial incentives that resulted from the challenges of health care reform is the development of clinically integrated networks (CINs). CINs sanctioned by the U.S. Department of Justice and Federal Communications Commission as a physician-led structure and includes both private and employed physician practices and healthcare network executives. A CIN is a structure with the purpose of aligning the collaboration between hospitals, healthcare networks, and health care providers. Participants decide on performance, quality, value, and efficiency goals and share profits resulting from the collaboration. CINs must comply with clinical guidelines and demonstrate measurable improvement. This format allows physicians' autonomy andpartnerships with healthcare organizations while sharing financial profits from the overall performance (52).

Other solutions for "performance-independent" measures, including restructuring physicians' reimbursement, should be considered for combating burnout. However, the current atmosphere and nationally proposed schedules for payments and funding schedules would make this recommendation unrealistic, if not elusive. Alternatively, employers, payors, and health plans should encourage physicians to embrace a better work-life balance by structuring compensation packages that incorporate schedule flexibility, retirement investment, and blended bonuses to compensate for any financial loss to physicians from additional paid time off (PTO) while incentivizing them to participate in leadership activities or local community initiatives.

\section{Conclusions}

Burnout results from job stress that accumulates over time and results in fatigue, cynicism, and a lost sense of control, contributing to disruptive behavior, lost workdays, and ultimately resignation or early retirement. The causes of burnout in the health professions are numerous, and the 
impact reverberates negatively throughout the organization and for their patients. The effects of burnout are not isolated to the workplace but often carry over into the health professional's personal life, impacting both the family and self. The inability to disconnect from the office and separate work from personal life has resulted in higher divorce rates, addiction \& substance abuse, and rates of suicide in medical workers. Health professionals, including nurses, Physician Assistants (PAs), pharmacists, and physicians, are more susceptible to burnout than the general population due to moral stress, increased regulations \& bureaucratic requirements, excessive hours and on-call responsibilities, and increased productivity requirements often stemming from advancements in EHR technology.

Strategies to mitigate burnout have been researched and studied throughout academia and the medical profession. Although many solutions have been identified, no single solution serves as the de facto cure for the prevalence of burnout among health professionals. This paper recommends a holistic approach to addressing burnout, including solutions targeting the whole person, social, behavioral, mental wellness, the workplace environment, and individual/organizational goals. For these reasons, health managers should be trained at detecting signs of burnout and being empowered by leadership to address the specific department's underlying causes. Early detection is paramount in preventing the spread of burnout in the healthcare organization. Managers must foster a supportive environment where defined programs are readily available for health providers. Developing peer support networks, increasing access to confidential mental-health resources, and producing promotional material on awareness and treatment options are necessary to diffuse a workforce high in burnout. Lastly, altering project and performance goals to incorporate personal time provides health professionals an outlet to "de-stress." Personal time is individualized and discretionary: medical staff must be encouraged to use this time for personal and professional improvement and tasks outside of their daily responsibilities. For example, this time must not be used to catch-up on projects, chart, or see walk-ins at work, but rather for personal relaxation \& enrichment regiments. Addressing burnout in the health professions requires a multifactorial approach that involves the complete support of leadership and frontline managers.

\section{Recommendations for future direction}

The strategies formed by the authors of this paper evolved as the course progressed, and a double-loop approach was used to validate the root causes of burnout. Thus, the authors initially limited the scope of the project to address burnout among physicians. However, if physicians are experiencing burnout, this increases the likelihood of burnout among nurses, P.A.s, and CNAs, representing the "frontline" of patient care. Positive intergroup relationships are essential for teams to function effectively (49). Therefore, expanding the paper to address burnout among the health professions will allow the authors to identify causes within a particular profession and sources of conflict and tension among the professions that may exacerbate burnout syndrome. After reassessing our strategy, the group agreed to expand the search to include other healthcare professions. Performing an in-depth literature review, we found an abundance of supportive evidence that burnout is prevalent in other health professions. However, the literature did validate that a higher percentage of physicians experienced burnout than the different professions-which supported why the group originally targeted physicians for the project. However, expanding our study to the other careers allowed the team to find trends in both causes and countermeasures that may have been overlooked if isolated to one profession. Finally, burnout represents a harmful condition that is plaguing modern medical institutions. Such occurrences represent a potential danger to the foundation of the medical professional, loss of possible revenue stream to the organization, and diminished patient care. By detecting and ultimately acknowledging the severity of the syndrome, managers and executives can better institute policies that minimize the resurgence of burnout syndrome. A multi-pronged approach is vital for identifying and treating the condition. A single "silver bullet" is not realistic for alleviating such a complex issue-with its cultural, social, personal, and institutional origins. With integrated and proper teamwork, a shared mindset, enabling conditions, a unified vision, and motivational factors, burnout can be both highlighted for its negative impact on the healthcare infrastructure and accepted as a legitimate medical condition requiring intervention and strategies to lessen its occurrence in the personal \& work spheres.

\section{Acknowledgments}

Funding: None.

\section{Footnote}

Reporting Checklist: The authors have completed the Narrative 
Review reporting checklist (available at https://jhmhp. amegroups.com/article/view/10.21037/jhmhp-20-153/rc).

Peer Review File: Available at https://jhmhp.amegroups.com/ article/view/10.21037/jhmhp-20-153/prf

Conflicts of Interest: All authors have completed the ICMJE uniform disclosure form (available at https://jhmhp. amegroups.com/article/view/10.21037/jhmhp-20-153/coif). The authors have no conflicts of interest to declare.

Ethical Statement: The authors are accountable for all aspects of the work in ensuring that questions related to the accuracy or integrity of any part of the work are appropriately investigated and resolved.

Open Access Statement: This is an Open Access article distributed in accordance with the Creative Commons Attribution-NonCommercial-NoDerivs 4.0 International License (CC BY-NC-ND 4.0), which permits the noncommercial replication and distribution of the article with the strict proviso that no changes or edits are made and the original work is properly cited (including links to both the formal publication through the relevant DOI and the license). See: https://creativecommons.org/licenses/by-nc-nd/4.0/.

\section{References}

1. Centers for Medicare and Medicaid Services. National Health Expenditure Data. 2017. Available online: https:// www.cms.gov/research-statistics-data-and-systems/ statistics-trends-and-reports/nationalhealthexpenddata

2. American Mobile Nurses Healthcare. Century Sourcing: Solving the Healthcare Supply-Demand. 2020. Available online: https://www.amnhealthcare.com/latest-healthcarenews/healthcare-supply-demand

3. Kavilanz P. The US can't keep up with demand for health aides, nurses and doctors. Available online: https://money. cnn.com/2018/05/04/news/economy/health-care-workersshortage/index.html

4. Maslach C, Leiter MP. Understanding the burnout experience: recent research and its implications for psychiatry. World Psychiatry 2016;15:103-11.

5. Cornell K. Physician Burnout: A History of the Not-SoRecent Phenomenon Plaguing Clinicians. 2019. Available online: https://www.spok.com/blog/physician-burnouta-history-of-the-not-so-recent-phenomenon-plaguingclinicians
6. Reith TP. Burnout in United States Healthcare Professionals: A Narrative Review. Cureus 2018;10:e3681.

7. Huang P. What's Doctor Burnout Costing America? Available online: https://www.npr.org/sections/healthshots/2019/05/31/728334635/whats-doctor-burnoutcosting-america

8. Han S, Shanafelt TD, Sinsky CA, et al. Estimating the Attributable Cost of Physician Burnout in the United States. Ann Intern Med 2019;170:784-90.

9. Powel A. Work highlights economic cost in lost time, turnover. Available online: https://news.harvard.edu/ gazette/story/2019/07/doctor-burnout-costs-health-caresystem-4-6-billion-a-year-harvard-study-says/

10. Kane L. Medscape National Physician Burnout, Depression \& Suicide Report. 2019. Available online: https://www.medscape.com/slideshow/2019-lifestyleburnout-depression-60110562019

11. Dewa CS, Loong D, Bonato S, et al. The relationship between physician burnout and quality of healthcare in terms of safety and acceptability: a systematic review. BMJ Open 2017;7:e015141.

12. Batra K, Singh TP, Sharma M, et al. Investigating the Psychological Impact of COVID-19 among Healthcare Workers: A Meta-Analysis. Int J Environ Res Public Health 2020;17:9096.

13. Shin A, Gandhi T, Herzig S. Make The Clinician Burnout Epidemic A National Priority. 2016. Available online: https://www.healthaffairs.org/do/10.1377/ hblog20160421.054511/full/

14. Park R. Why So Many Young Doctors Work Such Awful Hours. Available online: https://www.theatlantic. com/business/archive/2017/02/doctors-long-hoursschedules/516639/

15. University of South Florida Health. Federal Mandates for Healthcare: Digital Record-Keeping Requirements for Public and Private Healthcare Providers. Available online: https://www.usfhealthonline.com/resources/healthcare/ electronic-medical-records-manda

16. Hoffman S. Physician burnout: why legal and regulatory systems may need to step in. Available online: https:// theconversation.com/physician-burnout-why-legal-andregulatory-systems-may-need-to-step-in-119705

17. Jason C. Study Shows Physician Burnout Directly Related to EHRs. Available online: https://ehrintelligence.com/news/ study-shows-physician-burnout-directly-related-to-ehrs

18. Pearl R. The 3 Causes of Physician Burnout (And Why There's No Simple Solution). Available online: https:// www.forbes.com/sites/robertpearl/2019/09/09/burnout-3- 
causes/?sh=4a9f18b86a09

19. AHRQ. Physician Burnout. Available online: https:// www.ahrq.gov/prevention/clinician/ahrq-works/burnout/ index.html

20. Peckham C. Medscape National Physician Burnout \& Depression. Available online: https://www.medscape.com/ slideshow/2018-lifestyle-burnout-depression-6009235

21. Dyrbye LN, Thomas MR, Massie FS, et al. Burnout and suicidal ideation among U.S. medical students. Ann Intern Med 2008;149:334-41.

22. Embriaco N, Hraiech S, Azoulay E, et al. Symptoms of depression in ICU physicians. Ann Intensive Care 2012;2:34.

23. Tawfik DS, Profit J, Morgenthaler TI, et al. Physician Burnout, Well-being, and Work Unit Safety Grades in Relationship to Reported Medical Errors. Mayo Clin Proc 2018;93:1571-80.

24. Haas M, Mortensen M. The Secrets of Great Teamwork. Harv Bus Rev 2016;94:70-6, 117.

25. Rushton CH. Moral Resilience: A Capacity for Navigating Moral Distress in Critical Care. AACN Adv Crit Care 2016;27:111-9.

26. Lan YL, Huang WT, Kao CL, et al. The relationship between organizational climate, job stress, workplace burnout, and retention of pharmacists. J Occup Health 2020;62:e12079.

27. West CP, Dyrbye LN, Shanafelt TD. Physician burnout: contributors, consequences and solutions. J Intern Med 2018;283:516-29.

28. Gathers D. Diversity management: an imperative for healthcare organizations. Hosp Top 2003;81:14-20.

29. Dyrbye LN, West CP, Satele D, et al. Burnout among U.S. medical students, residents, and early career physicians relative to the general U.S. population. Acad Med 2014;89:443-51.

30. Langballe EM, Innstrand ST, Aasland AG, et al. The predictive value of individual factors, work-related factors, and work-home interaction on burnout in female and male physicians: a longitudinal study. Stress \& Health 2011;27:73-87.

31. Patel RS, Bachu R, Adikey A, et al. Factors Related to Physician Burnout and Its Consequences: A Review. Behav Sci (Basel) 2018;8:98.

32. Blechter B, Jiang N, Cleland C, et al. Correlates of Burnout in Small Independent Primary Care Practices in an Urban Setting. J Am Board Fam Med 2018;31:529-36.

33. Edwards ST, Marino M, Balasubramanian BA, et al. Burnout Among Physicians, Advanced Practice Clinicians and Staff in Smaller Primary Care Practices. J Gen Intern Med 2018;33:2138-46.

34. Kotter JP. Leading Change: Why Transformation Efforts Fail. Harvard Business Review (May-June 1995).

35. Turner JD. Why are Doctors Burning Out? And 3 Ways FI Can Save Them. Available online: https:// thephysicianphilosopher.com/fi-saves-medicine/

36. Shanafelt TD, Gorringe G, Menaker R, et al. Impact of organizational leadership on physician burnout and satisfaction. Mayo Clin Proc 2015;90:432-40.

37. Williams ES, Konrad TR, Linzer M, et al. Physician, practice, and patient characteristics related to primary care physician physical and mental health: results from the Physician Worklife Study. Health Serv Res 2002;37:121-43.

38. Health IT Dashboard. Non-federal acute care hospital electronic health record adoption. Available online: https:// dashboard.healthit.gov/quickstats/pages/physician-ehradoption-trends.php

39. Cohen DJ, Dorr DA, Knierim K, et al. Primary Care Practices' Abilities And Challenges In Using Electronic Health Record Data For Quality Improvement. Health Aff (Millwood) 2018;37:635-43.

40. Hemler JR, Hall JD, Cholan RA, et al. Practice Facilitator Strategies for Addressing Electronic Health Record Data Challenges for Quality Improvement: EvidenceNOW. J Am Board Fam Med 2018;31:398-409.

41. Arndt BG, Beasley JW, Watkinson MD, et al. Tethered to the EHR: Primary Care Physician Workload Assessment Using EHR Event Log Data and Time-Motion Observations. Ann Fam Med 2017;15:419-26.

42. Moss M, Good VS, Gozal D, et al. An Official Critical Care Societies Collaborative Statement: Burnout Syndrome in Critical Care Healthcare Professionals: A Call for Action. Crit Care Med 2016;44:1414-21.

43. Drummond D. The Tools. Stop Physician Burnout: What to Do When Working Harder Isn't Working: Heritage Press Publications, 2014:83-144.

44. Shanafelt TD, West CP, Sinsky C, et al. Changes in Burnout and Satisfaction With Work-Life Integration in Physicians and the General US Working Population Between 2011 and 2017. Mayo Clin Proc 2019;94:1681-94.

45. Lilly CM, Cucchi E, Marshall N, et al. Battling Intensivist Burnout: A Role for Workload Management. Chest 2019;156:1001-7.

46. Nohria N, Groysberg B, Lee L. Employee motivation: a powerful new model. Harvard Business Review 2008;86:78-84.

47. Drummond D. Physician Burnout: Its Origin, Symptoms, 
and Five Main Causes. Fam Pract Manag 2015;22:42-7.

48. Bernstein E, Nohria N. Note on Organizational Structure. Harvard Business School, 2016.

49. Burns L, Bradley E, Weiner B. Organizational design and behavior Shortell and Kaluzny's healthcare management. 7 ed. Clifton Park, NY: Delmar Cengage Learning, 2019.

50. Center for Disease Control and Prevention. Writing SMART Objectives. Available online: https://www.cdc.

doi: $10.21037 /$ jhmhp-20-153

Cite this article as: Tanios $M$, Haberman D, Bouchard J, Motherwell M, Patel J. Analyses of burn-out among medical professionals and suggested solutions-a narrative review. J Hosp Manag Health Policy 2022;6:7. gov/healthyyouth/evaluation/pdf/brief3b.pdf

51. Tedeschi RG, Calhoun LG. Posttraumatic Growth: Conceptual Foundations and Empirical Evidence. Psychological Inquiry 2004;15:1-18.

52. Kumar P, Levine E. Clinically integrated networks: Can they create value? Available online: https://healthcare. mckinsey.com/clinically-integrated-networks-can-theycreate-value/2016 